\title{
Correction to: Test-retest reliability of the computer-assisted DIA-X-5 interview for mental disorders
}

Jana Hoyer ${ }^{1,2}$, Catharina Voss ${ }^{1,2}$, Jens Strehle ${ }^{1,3}$, John Venz ${ }^{1,2,3}$, Lars Pieper ${ }^{1,2,3}$, Hans-Ulrich Wittchen ${ }^{4}$, Stefan Ehrlich ${ }^{5,6}$ and Katja Beesdo-Baum ${ }^{1,2,3^{*}}$

\section{Correction to: BMC Psychiatry (2020) 20:280 https://doi.org/10.1186/s12888-020-02653-6}

Following the publication of the original article [1], multiple errors were identified in the Results Text of the Abstract and the Diagnostic agreement for DSM-5 disorder categories section.

The text has been changed to correspond to the correct results reported in Table 4 and are highlighted in bold typeface.

Abstract - Results:

Kappa values ranged from 0.90 for post-traumatic stress disorder to $\mathbf{0 . 2 9}$ for social anxiety disorder.

Main text - Diagnostic agreement for DSM-5 disorder categories:

The highest JI, 1.00, was found for anorexia nervosa, second highest JI (0.91) was found for 'any' DSM-5 disorder. PTSD had a JI of 0.83 .

The category of any anxiety disorder (without panic attack) revealed lowest RJI with 0.69 , followed by social anxiety disorder with an RJI of 0.79; the RJI for any anxiety disorder (without social anxiety disorder) was 0.76 .

Most Cohen's kappa values ranged between $0.70-0.85$, with anorexia nervosa displaying the highest kappa (1.00), followed by PTSD (0.90) and cannabis use disorder (0.88). The diagnosis of 'any' DSM-5 disorder had a kappa of $\mathbf{0 . 8 5}$.

\section{Author details}

${ }^{1}$ Institute of Clinical Psychology and Psychotherapy, Technische Universität Dresden, Dresden, Germany. ${ }^{2}$ Behavioral Epidemiology, Faculty of Psychology, Technische Universität Dresden, Dresden, Germany. ${ }^{3}$ Center for Clinical Epidemiology and Longitudinal Studies, Technische Universität Dresden, Dresden, Germany. ${ }^{4}$ Department of Psychiatry \& Psychotherapy, Ludwig-Maximilians-Universität, Munich, Germany. ${ }^{5}$ Division of Psychological and Social Medicine and Developmental Neurosciences, Faculty of Medicine, TU Dresden, Dresden, Germany. ${ }^{6}$ Eating Disorders Research and Treatment Center, Deartment of Child and Adolescent Psychiatry, Faculty of Medicine,

TU Dresden, Dresden, Germany.

Published online: 09 July 2020

\section{Reference}

1. Hoyer J, et al. Test-retest reliability of the computer-assisted DIA-X-5 interview for mental disorders. BMC Psychiatry. 2020;20:280. https://doi.org/ 10.1186/s12888-020-02653-6.

The original article can be found online at https://doi.org/10.1186/s12888020-02653-6.

* Correspondence: Katja.Beesdo-Baum@tu-dresden.de

${ }^{1}$ Institute of Clinical Psychology and Psychotherapy, Technische Universität Dresden, Dresden, Germany

${ }^{2}$ Behavioral Epidemiology, Faculty of Psychology, Technische Universität Dresden, Dresden, Germany

Full list of author information is available at the end of the article

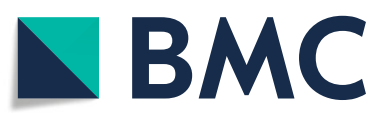

(c) The Author(s). 2020 Open Access This article is licensed under a Creative Commons Attribution 4.0 International License, which permits use, sharing, adaptation, distribution and reproduction in any medium or format, as long as you give appropriate credit to the original author(s) and the source, provide a link to the Creative Commons licence, and indicate if changes were made. The images or other third party material in this article are included in the article's Creative Commons licence, unless indicated otherwise in a credit line to the material. If material is not included in the article's Creative Commons licence and your intended use is not permitted by statutory regulation or exceeds the permitted use, you will need to obtain permission directly from the copyright holder. To view a copy of this licence, visit http://creativecommons.org/licenses/by/4.0/. The Creative Commons Public Domain Dedication waiver (http://creativecommons.org/publicdomain/zero/1.0/) applies to the data made available in this article, unless otherwise stated in a credit line to the data. 